\title{
Clinical and Biochemical Variation and Family Studies in the Multiple Acyl-CoA Dehydrogenation Disorders
}

\author{
WILLIAM J. RHEAD, JON A. WOLFF, MARK LIPSON, PEGGY FALACE, NIRMALA DESAI, \\ KATHIE FRITCHMAN, ANNE MOON, AND LAWRENCE SWEETMAN \\ Department of Pediatrics, University of Iowa, Iowa City, Iowa 52242 [W.J.R., K.F., A.M.J; Department of \\ Pediatrics, University of California, San Diego, La Jolla, California 92093 [J.A.W., L.S.]; Department of \\ Pediatrics, Permanente Medical Group, Sacramento, California 95825 [M.L.]; and Departments of Pathology \\ and Pediatrics, University of Kentucky, Lexington, Kentucky 40531 [P.F., N.D.]
}

\begin{abstract}
We report clinical and biochemical studies in patients with multiple acyl-CoA dehydrogenation disorders (MAD) and their parents. A severely affected (MAD:S) patient presented with neonatal acidosis leading to death and excreted a wide range of straight- and branched-chain acyl $\mathrm{CoA}$ derivatives. Two patients with mild variants of the same disorder (MAD:M) presented with neurologic abnormalities, acidotic coma, and/or poor growth; they primarily excreted ethylmalonate and variable amounts of adipate. Fibroblasts from the MAD:S patient demonstrated severely defective radiolabeled substrate oxidation, while the MAD:M cells had milder oxidative defects. Fibroblasts from two other MAD:M and six other MAD:S patients demonstrated analogous defects in substrate oxidation. As a group, MAD:S cells deficient in electron transfer flavoprotein:ubiquinone oxidoreductase had significantly lower residual oxidative activities than did MAD:S cells deficient in electron transfer flavoprotein. Fibroblasts from the parents of four MAD:S patients oxidized radiolabeled substrates significantly less effectively than did normal infant controls but were indistinguishable from normal adult cells. We found relatively higher residual oxidative activities in maternal than in paternal cells. Amniocytes from a fetus at risk for MAD:S catabolized labeled substrates normally; the infant has been clinically and biochemically normal up to 30 months of age. (Pediatr Res 21: 371-376, 1987)
\end{abstract}

\section{Abbreviations}

ETF, electron transfer flavoprotein ETF:QO, ETF:coenzyme Q oxidoreductase

MAD, multiple acyl-CoA dehydrogenation disorder

MAD:M, MAD, mild variant

MAD:S, MAD, severe variant

MCT, medium-chain triglycerides

FBS, fetal bovine serum

Received June 5, 1986; accepted November 21, 1986.

Address correspondence and reprint requests to Lawrence Sweetman, Ph.D., Department of Pediatrics, The University of California, San Diego, La Jolla, CA 92093

This work was supported in part by USPHS Grants HD04608 (L.S.), HD00380 (W. J. R.), AM33289 (W. J. R.) National Foundation March of Dimes Grants 5 297 and $1-876$ (W. J. R.), a grant from the Muscular Dystrophy Association (W. J. R.), and Grant MCJ 04007 from the Health Services Administration, DHHS (L. S.).
MAD include glutaric aciduria type II (1-9), ethylmalonicadipic aciduria (10), and $\mathrm{C}_{6}-\mathrm{C}_{10}$ dicarboxylic aciduria responsive to riboflavin (11). Most MAD:S patients present shortly after birth with severe hypoglycemia and profound metabolic acidosis but without ketosis $(1-8,12)$. Hypotonia and seizures are common symptoms $(1-7,12)$. Some patients have "sweaty-foot" or acrid odor $(1-3,5,7)$; most do not survive the neonatal period $(1,3-5,7)$ although some have lived for months $(6,12)$. MAD:M patients have presented at $7 \mathrm{wk}$ to $19 \mathrm{yr}$ of age with less severe and more variable clinical symptoms, including intermittent hypoketotic hypoglycemia, acidosis, and coma (9-11). The characteristic metabolites elevated in most MAD patients include glutaric acid, ethylmalonic acid, and adipic acid in widely varying proportions $(1-12)$. The volatile short-chain fatty acids, isobutyric acid, butyric acid, 2-methylbutyric acid, isovaleric acid, and hexanoic acid $(1,3-5,7,10,12)$ and their glycine conjugates $(2$, $4,6,10-12)$ are elevated in many cases, as is the amino acid sarcosine $(2-4,12)$. The clinical and biochemical heterogeneity of these disorders reflect varying deficiencies of either ETF or its dehydrogenase (ETF:QO), thought to be the primary biochemical defects (13). Herein we describe the clinical features and metabolite elevations of one new MAD:S and two new MAD:M patients with widely differing clinical presentations. We also report oxidation studies using fibroblasts from these three patients, from eight previously identified MAD patients and from eight parents of four of the MAD:S patients.

\section{CASE REPORTS}

Patient 1401 (C.W) was a $3600 \mathrm{~g}$ term infant born to a gravida 4 para 4 mother after an uneventful pregnancy, labor, and delivery. At $24 \mathrm{~h}$ of age, he developed postprandial vomiting and hypoglycemia. Shortly thereafter he developed increasing metabolic acidosis, respiratory distress, and suffered a cardiopulmonary arrest. He was resuscitated, ventilated, and transferred to the University of Kentucky Medical Center. At admission, he was noted to have a dark brown urine with a distinct musty odor. A work-up for inborn errors of metabolism was begun. An initial physical examination was remarkable only for unresponsiveness. Arterial pHs were 7.29 or below. Peripheral blood glucose was $58 \mathrm{mg} / 100 \mathrm{ml}$ with a cerebrospinal fluid glucose of $14 \mathrm{mg} / 100 \mathrm{ml}$. Blood ammonia was $210 \mu \mathrm{M}$. During the 2 nd hospital day, he developed irregular ventricular rhythms and episodic hypotension. He was transiently stabilized with cardioversion and lidocaine, but developed clonic seizures. A second episode of ventricular tachycardia was successfully treated but irreversible hypotension developed and he died at 3 days of age 
after he developed a idioventricular rhythm. Postmortem biochemical studies of urine demonstrated the organic aciduria of MAD:S (see "Results"). An autopsy revealed diffuse fatty changes affecting virtually all hepatocytes and focal pulmonary hemorrhage. Facial features and microscopic examination of the kidneys were normal. This child has three siblings in good health; the parents are of Northern European origin and are nonconsanguineous.

Patient 840 (M.L.) is a 6-yr-old boy born by an uncomplicated cesarean section for breech presentation. At birth, he weighed 9 lb $2 \mathrm{oz}$ and Apgars were 9 and 9 at 1 and $5 \mathrm{~min}$. His milestones were slow and he walked at 18 months. At 34 months his speech was limited to single words. At age 22 months, he had a febrile illness followed by gait difficulty and irritability for $1 \mathrm{wk}$. Over the next 7 months he had two episodes of febrile illnesses followed by $12-\mathrm{h}$ periods of shaking and fine tremors. At age 34 months he was admitted to the hospital when he developed seizures and coma after a febrile illness. He was mildly acidotic with a serum bicarbonate level of $16 \mathrm{mEq} /$ liter (normal 24-28). His urine ketones were $1+$. His blood ammonia and glucose were normal. Serum and urine amino acid screens were normal. Urinary organic acids were abnormal (see "Results"). When the diagnosis of MAD:M was suspected, he was started on a low fat diet consisting of Vivonex HN, supplemented initially with safflower oil but currently with fruits, cereal, and yogurt. A trial with oral riboflavin supplements was performed (see "Results"). While he has had slow improvement in his neurological status, 16 months after admission he continues to have quadriparesis and ankle clonus. He has no recognizable speech, although he appears to hear. He is able to swallow from a cup, but drools a great deal. He takes daily phenobarbital. He has been admitted on two subsequent occasions for pneumonia but had no signs of metabolic decompensation. Total plasma carnitine was $34 \mu \mathrm{M}$ (normal $50 \pm 10 \mu \mathrm{M}$ ), with free and esterified fractions of $25 \mu \mathrm{M}$ (normal $45 \pm 10 \mu \mathrm{M}$ ) and $9 \mu \mathrm{M}$ (normal $5 \pm 5 \mu \mathrm{M}$ ), respectively. The mother is of Irish, Scotch, German, and Norwegian ancestry, and the father is of Yugoslavian ancestry; they are nonconsanguineous. This child has two older brothers who have been evaluated for hyperkinesis, poor coordination, and academic difficulties. They and their parents excrete no abnormal organic acids (data not shown).

Patient 930 (P.K.) is a $3 \frac{1}{1} 2$-yr-old American boy of Greek ancestry whose major problems have been slow physical and mental development. He was a 36-wk, 2268-g baby born to a 42yr-old mother following a pregnancy complicated by placenta previa. The mother was hospitalized 3 months prior to delivery for impending premature delivery. Delivery was by cesarean section with no perinatal distress. In the newborn period, he fed poorly and failed to breast-feed successfully.

Following birth, he grew poorly; at $1 \mathrm{yr}$ of age, his weight age was 3 months and his height age was 6 months. Since 1 yr of age he has remained far below the fifth percentile in both weight and height. At $3 \mathrm{yr}$ of age, his weight age is 10 months and his length age is 18 months. His head circumference has increased along the 25 th percentile since birth.

He has had delayed psychomotor development, especially noticeable since 6 months of age, and has lost some previously acquired abilities. He smiled at 2 months of age, rolled over at 4 months, and sat at 8 months. At 2 yr of age he had a 25 -word vocabulary, mostly understandable to family only, but by $2 \frac{1}{2} \mathrm{yr}$ of age he was no longer speaking. At $3^{1 / 2}$ yr of age he is beginning to speak again (five words only). At 13 months of age, he became mobile by scooting in a sitting position on his buttocks and moving forward on his hands. At 15 months of age he began pulling himself to standing position but stopped standing at $2 \mathrm{yr}$ of age. At $3 \mathrm{yr}$ of age he began standing and walking and now at $3 \frac{1}{2}$ yr of age he can run.

He has had no episodes of vomiting, lethargy, acidosis, ketosis, or hypoglycemia. Physical examination has been remarkable only for mild hyperreflexia in the lower extremities. Routine laboratory investigations have all been within normal limits. CT scans of the head at $1 \frac{1 / 2}{2}$ and 3 yr of age have been normal. An EEG at $3 \mathrm{yr}$ of age was normal. Ethylmalonic and adipic acids were first found in the urine at $1 \frac{1 / 2}{\mathrm{yr}}$ of age; at that age he tolerated challenges of $450 \mathrm{mg}$ of MCT oil $/ \mathrm{kg} /$ day (divided three times a day) and $180 \mathrm{mg}$ of lysine $/ \mathrm{kg} /$ day without any vomiting, lethargy, or ketoacidosis. His mental and physical development was not improved by an 8 -month trial of $250 \mathrm{mg}$ of glycine $/ \mathrm{kg} /$ day supplementation or by a low fat diet (with poor compliance). Total plasma carnitine was $84 \mu \mathrm{M}$, with free and esterified fractions of 62 and $22 \mu \mathrm{M}$, respectively.

\section{METHODS}

Metabolite analyses. Nonvolatile urinary organic acids were analyzed by sequential liquid partition chromatography, gas chromatography, and gas chromatography-mass spectrometry as previously described (14). Volatile short-chain fatty acids were quantified by direct injections of acidified urine and plasma and gas chromatography as previously described (14).

Materials. All chemicals used were reagent grade (Sigma Chemical Company, St. Louis, MO). All tissue culture reagents and media were from Kansas City Biologicals, Kansas City, MO. $\left[1-{ }^{14} \mathrm{C}\right]$ butyrate, $\left[1-{ }^{14} \mathrm{C}\right]$ octanoate, and $\left[1,4-{ }^{14} \mathrm{C}\right]$ succinate were obtained from New England Nuclear Corporation, Boston, MA and $\left[9,10(\mathrm{n})-{ }^{3} \mathrm{H}\right]$ palmitate and $\mathrm{L}-\left[2-{ }^{14} \mathrm{C}\right]$ leucine from Research Products International, Arlington Heights, IL.

Cell culture. Untransformed cultures of normal diploid skin fibroblasts were established by accepted techniques immediately after biopsy. Skin biopsies were obtained at necropsy 6 to $18 \mathrm{~h}$ after death from six adults without clinical evidence of inborn errors of metabolism, a 29-yr-old man (line S-1), a 54-yr-old man (S-3), and 57-, 74-, 71-, and 64-yr-old women (S-5, -6, -7, $-8)$; cultures $\mathrm{S}-2$ and -4 were established from skin biopsies of a healthy 35 -yr-old man and 24 -yr-old woman, respectively. Control cell cultures were derived from the foreskins of 10 randomly selected, healthy full-term male infants. Skin fibroblasts were obtained from seven MAD:S patients who presented in the neonatal period, three female (1540, Ref. $4 ; 1441$, Ref. $6 ; 1520$, Ref. 15) and four males (1400, Ref. 1; 1430, Ref. 12; 1515, Ref. 5; 1401). The MAD:M patients included one female (493, Ref. 10 ) and three males (741, patient B.K. in Ref. 16;840 and 930), who all presented in infancy. Cells were subcultured serially $(1: 4)$ at 7- to 9-day intervals in Eagle's minimal essential medium containing $10 \% \mathrm{FBS}, 2 \mathrm{mM}$ glutamine, $140 \mu \mathrm{M}$ penicillin, 86 $\mu \mathrm{M}$ streptomycin, and $162 \mu \mathrm{M}$ neomycin. Cells in passages 6 to 20 were used in all experiments. Amniocyte culture was performed using the methods described for fibroblasts.

${ }^{14} \mathrm{C}$-substrate oxidation to ${ }^{14} \mathrm{CO}_{2}$ by intact fibroblasts in suspension was performed precisely as described earlier, using ${ }^{14} \mathrm{C}$ substrates at previously reported specific activities and concentrations $(17,18)$. Oxidation studies were done 7 to 9 days after subculture (1:4) when the monolayers were confluent. Less than $5 \%$ of the label from any ${ }^{14} \mathrm{C}$-substrate was converted to ${ }^{14} \mathrm{CO}_{2}$ in these experiments $(17) \cdot\left[9,10(\mathrm{n})-{ }^{3} \mathrm{H}\right]$ palmitate oxidation was quantitated by measuring ${ }^{3} \mathrm{H}$ released into water by cell monolayers in $2 \mathrm{~cm}^{2}$ microtiter wells. The specific activity, concentration and incubation time were $380 \mathrm{mCi} / \mathrm{mmol}, 22 \mu \mathrm{M}$ and $2 \mathrm{~h}$, respectively. The ${ }^{3} \mathrm{H}_{2} \mathrm{O}$ produced was separated from unreacted substrate by anion exchange chromatography on AG-1 (Biorad) as described earlier (19). Less than $2 \%$ of the ${ }^{3} \mathrm{H}$ on the substrate was converted to ${ }^{3} \mathrm{H}_{2} \mathrm{O}$ (Moon $\mathrm{A}$, Rhead W, unpublished data).

${ }^{14} \mathrm{C}$ incorporation from labeled substrates into cellular protein was determined by the method described previously (17); the culture medium used was Leibowitz L-15 containing 10\% FBS and $20 \mathrm{mM}$ HEPES, pH 7.2; the specific activities and concentrations of both $\left[1-{ }^{14} \mathrm{C}\right]$ butyrate and -octanoate were $10 \mathrm{mCi}$ / $\mathrm{mmol}$ and $0.1 \mathrm{mM}$, respectively. The specific activity and concentration of $\left[1,4-{ }^{14} \mathrm{C}\right]$ succinate were $1.0 \mathrm{mCi} / \mathrm{mmol}$ and 1.0 $\mathrm{mM}$, respectively. Less than $7 \%$ of the label from any ${ }^{14} \mathrm{C}$ - 
substrate was incorporated into cellular protein in these experiments (17). Incubation time was $22 \mathrm{~h}$; protein was determined by a fluorometric method (20). All $p$ values cited are two-tailed and calculated by Student's $t$ test, and compare infant's or parent's values to control values, unless stated otherwise.

\section{RESULTS}

ETF-deficient patient 1401 had the large elevations of shortchain fatty acids in serum and urine characteristic of MAD:S (Tables 1 and 2). Glycine conjugates of these acids were not detected. The most highly elevated acid in urine obtained postmortem was glutaric acid; ethylmalonic and adipic acids were also elevated (Table 2). The levels of other elevated acids in $\mu \mathrm{mol} / \mathrm{mg}$ creatinine were: 1.29 methylsuccinic acid, 0.45 suberic

Table 1. Short-chain fatty acid levels in patient $1401^{*}$

\begin{tabular}{lcccc}
\hline & Isobutyric & Butyric & 2-Methylbutyric & Isovaleric \\
\hline \multicolumn{5}{c}{ Serum $(\mu$ mol/liter $)$} \\
Patient 1401 & 4740 & 1091 & 921 & 564 \\
Normals & $<1.8$ & $<2.5$ & $<0.3$ & $<0.4$
\end{tabular}

Urine ( $\mu \mathrm{mol} / \mathrm{mg}$ creatinine)

\begin{tabular}{lrrrr} 
Patient 1401 & 2.72 & 5.08 & 0.31 & 0.80 \\
Normals & $<0.08$ & $<0.08$ & $<0.08$ & $<0.08$ \\
\hline
\end{tabular}

* Normal values from Sweetman et al. (3). acid, 0.10 sebacic acid, 4.33 2-hydroxyglutaric acid, 80.18 hippuric acid, 37.13 4-hydroxyphenyllactic acid, and 21.49 lactic acid. Sarcosine was not detected.

The initial urine specimen of ETF-deficient patient 840 , obtained when he was comatose, contained large amounts of 4hydroxyhippuric acid ( $>15 \mu \mathrm{mol} / \mathrm{mg}$ creatinine) and a small elevation of ethylmalonic acid without an elevation of glutaric or adipic acids (Table 2). Treatment with riboflavin (100-500 $\mathrm{mg} /$ day) appeared to decrease initially the excretion of ethylmalonic acid with a later return to pretreatment levels.

ETF-deficient patient 930 initially had very small elevations of ethylmalonic and adipic acids (Table 2). Administration of $3.3 \mathrm{~g} \mathrm{MCT}$ in three divided doses caused a moderate increase in the excretion of ethylmalonic, adipic, and glutaric acids. Simultaneous administration of glycine abolished the increase seen with MCT alone, although hexanoylglycine was not detected. Administration of an oral load of lysine did not cause increased excretion of glutaric acid. A fat-free diet decreased the excretions of the acids to below the limit of detection.

Cells from these and other MAD patients oxidized radiolabeled substrates less effectively than did normal controls (Table 3). MAD:M cells oxidized $\left[1-{ }^{14} \mathrm{C}\right]$ butyrate at $28 \%$ (493) to $57 \%$ (930) of control levels and averaged $46 \%$ of control levels $(p<$ $0.05)$. With $\left[9,10(\mathrm{n})-{ }^{3} \mathrm{H}\right]$ palmitate as substrate, activities ranged from $31 \%$ (493) to $63 \%$ (741) of control. As a group, the MAD:M cells oxidized ${ }^{3} \mathrm{H}$-palmitate at $48 \%$ of control levels $(p=0.01)$. Analogously, ETF-deficient cells 840 and 930 oxidized $\left[1-{ }^{14} \mathrm{C}\right]$ octanoate at 47 and $55 \%$ of control levels $(p<0.05)$. Higher levels of residual activity were seen in the $\mathrm{L}-\left[2-{ }^{14} \mathrm{C}\right]$ leucine oxidations. MAD:M cells oxidized this substrate at $27 \%$ (493) to

Table 2. Urinary levels of organic acids

\begin{tabular}{|c|c|c|c|c|c|}
\hline Patient log no. & Collection date & Treatment & Glutaric & Ethylmalonic & Adipic \\
\hline & & & \multicolumn{3}{|c|}{$\mu \mathrm{mol} / \mathrm{mg}$ creatinine } \\
\hline ETF-deficient patient 1401 & DOB $11 / 11 / 79$ & & & & \\
\hline 7547 & $11 / 14 / 84$ & Postmortem & 83.55 & 3.50 & 5.32 \\
\hline ETF-deficient patient 840 & DOB $5 / 4 / 79$ & & & & \\
\hline A617 & $\operatorname{Recd} 3 / 31 / 82$ & & * & 0.773 & \\
\hline A662 & $4 / 5 / 82$ & & $*$ & 1.132 & 0.092 \\
\hline A789 & $4 / 27 / 82$ & & $*$ & 0.583 & 0.069 \\
\hline A 885 & $5 / 21 / 82$ & & $*$ & 0.313 & 0.074 \\
\hline A.1539 & $10 / 19 / 84$ & Baseline & $<0.010$ & 0.057 & $<0.010$ \\
\hline A 1697 & $11 / 29 / 82$ (24-h urine) & Riboflavin: $50 \mathrm{mg}$ bid $3 \mathrm{wk}$ & $<0.010$ & 0.048 & \\
\hline A 1698 & $11 / 29 / 82$ (24-h urine) & $50 \mathrm{mg}$ bid $3 \mathrm{wk}$ & $<0.010$ & 0.090 & 0.040 \\
\hline A 1970 & $1 / 20 / 83$ & $500 \mathrm{mg} \mathrm{qD}$ & $<0.010$ & 0.197 & 0.023 \\
\hline A1971 & $1 / 20 / 83$ & $500 \mathrm{mg} \mathrm{qD}$ & $*$ & 0.324 & 0.024 \\
\hline ETF-deficient patient 930 & DOB $3 / 28 / 81$ & & & & \\
\hline A1342 & $8 / 25 / 82$ & & $<0.010$ & 0.151 & 0.245 \\
\hline A 1362 & $9 / 2 / 82$ & & $<0.010$ & 0.105 & 0.020 \\
\hline A 1507 & $10 / 11-12 / 82$ & Baseline: Isomil & $<0.10$ & 0.105 & $<0.010$ \\
\hline A 1508 & $10 / 12-13 / 82$ & MCT: $1.1 \mathrm{~g}$ tid & * & 0.390 & 0.361 \\
\hline A 1526 & $10 / 15-16 / 82$ & $\begin{array}{l}\text { MCT: } 1.1 \mathrm{~g} \mathrm{tid} \\
\text { Glycine: } 250 \mathrm{mg} / \mathrm{kg} / \text { day }\end{array}$ & * & 0.160 & 0.055 \\
\hline A 1527 & $10 / 16-17 / 82$ & Lysine: $60 \mathrm{mg} / \mathrm{kg} /$ day & $<0.010$ & 0.180 & 0.156 \\
\hline A 1528 & $10 / 17-18 / 82$ & Lysine: $600 \mathrm{mg} / \mathrm{kg} / \mathrm{day}$ & $<0.010$ & 0.038 & 0.014 \\
\hline A1769 & $12 / 13-14 / 82$ & Low fat; glycine $250 \mathrm{mg} / \mathrm{kg} /$ day & $*$ & 0.031 & $<0.010$ \\
\hline A 1873 & $1 / 7 / 83$ & No fat & $*$ & $<0.010$ & $<0.010$ \\
\hline A2 2157 & $3 / 4 / 83$ & & $<0.010$ & 0.056 & $<0.010$ \\
\hline A2469 & $4 / 30 / 83$ & & $*$ & 0.346 & 0.112 \\
\hline $\mathrm{A} 2828$ & $7 / 19 / 86$ & $18 \%$ fat & $*$ & 0.209 & 0.092 \\
\hline A3174 & $10 / 3 / 83$ & & * & 0.117 & 0.019 \\
\hline A4078 & $2 / 5 / 84$ & Well & * & 0.129 & 0.039 \\
\hline A4079 & $3 / 10 / 84$ & Sick & $<0.010$ & 0.153 & 0.058 \\
\hline Normal $(n=10)$ & & & $<0.10$ & $<0.010$ & $<0.100$ \\
\hline
\end{tabular}

* No glutarate was detected in these urines, although its elution near the internal standard prevented its quantitation. 
Table 3. Oxidation of labeled substrates by intact patient fibroblast ${ }^{*}$

\begin{tabular}{|c|c|c|c|c|c|}
\hline Cell cultures & {$\left[1-{ }^{14} \mathrm{C}\right]$ butyrate } & {$\left[9,10(\mathrm{n})-{ }^{3} \mathrm{H}\right]$ palmitate } & $\mathrm{L}-\left[2-{ }^{14} \mathrm{C}\right]$ leucine & {$\left[1-{ }^{14} \mathrm{C}\right]$ octanoate } & {$\left[1,4-{ }^{14} \mathrm{C}\right]$ succinate } \\
\hline & \multicolumn{5}{|c|}{$\mathrm{nmol}{ }^{14} \mathrm{CO}_{2}$ or ${ }^{3} \mathrm{H}_{2} \mathrm{O}$ produced $/ \mathrm{mg}$ protein $/ \mathrm{h} \pm \mathrm{SEM}$} \\
\hline Normal infant controls & $5.54 \pm 0.48$ & $0.40 \pm 0.036$ & $1.87 \pm 0.14$ & $2.77 \pm 0.26$ & $1.82 \pm 0.21$ \\
\hline \multicolumn{6}{|l|}{ MAD:M } \\
\hline \multicolumn{6}{|l|}{ ETF:QO deficient } \\
\hline 493 & $1.55 \pm 0.33$ & $0.12 \pm 0.022$ & $0.50 \pm 0.20$ & ND & $1.35 \pm 0.21$ \\
\hline 741 & $3.10 \pm 0.35$ & $0.25 \pm 0.021$ & $1.19 \pm 0.32$ & ND & $1.64 \pm 0.27$ \\
\hline \multicolumn{6}{|l|}{ ETF deficient } \\
\hline 840 & $2.33 \pm 0.29$ & $0.22 \pm 0.009$ & $0.88 \pm 0.17$ & $1.30 \pm 0.22$ & $1.78 \pm 0.22$ \\
\hline 930 & $3.16 \pm 0.48$ & $0.18 \pm 0.032$ & $1.40 \pm 0.15$ & $1.52 \pm 0.25$ & $1.91 \pm 0.23$ \\
\hline \multicolumn{6}{|l|}{ MAD:S } \\
\hline \multicolumn{6}{|l|}{ ETF deficient } \\
\hline 1400 & ND & $0.07 \pm 0.007$ & ND & ND & ND \\
\hline 1401 & $0.50 \pm 0.09$ & $0.02 \pm 0.004$ & $0.30 \pm 0.08$ & ND & $2.00 \pm 0.49$ \\
\hline 1430 & $0.55 \pm 0.16$ & $0.03 \pm 0.017$ & $0.32 \pm 0.10$ & ND & $2.26 \pm 0.45$ \\
\hline 1441 & $0.50 \pm 0.11$ & $0.04 \pm 0.002$ & $0.22 \pm 0.13$ & ND & $1.71 \pm 0.73$ \\
\hline \multicolumn{6}{|l|}{ ETF:QO deficient } \\
\hline 1515 & $0.22 \pm 0.10$ & $0.01 \pm 0.002$ & $0.15 \pm 0.08$ & ND & $2.07 \pm 0.51$ \\
\hline 1520 & $0.17 \pm 0.05$ & $0.01 \pm 0.003$ & $0.14 \pm 0.05$ & ND & $1.27 \pm 0.26$ \\
\hline 1540 & $0.33 \pm 0.14$ & $0.01 \pm 0.001$ & $0.22 \pm 0.05$ & ND & $2.31 \pm 0.79$ \\
\hline
\end{tabular}

* The number of determinations ranged from 14 to 43 for control cultures and two to 15 for individual MAD cultures; ND, not determined.

Table $4 .{ }^{14} \mathrm{C}$ incorporation from labeled substrates into cellular protein of intact patient fibroblasts

\begin{tabular}{|c|c|c|c|}
\hline Cell cultures & {$\left[1-{ }^{14} \mathrm{C}\right]$ butyrate } & {$\left[1-{ }^{14} \mathrm{C}\right]$ octanoate } & {$\left[1,4-{ }^{14} \mathrm{C}\right]$ succinate } \\
\hline \multicolumn{4}{|c|}{$\mathrm{nmol}{ }^{14} \mathrm{C}$ incorporated $/ \mathrm{mg}$ protein $/ \mathrm{h} \pm S E M$} \\
\hline Normal infant controls & $0.68 \pm 0.06$ & $0.23 \pm 0.02$ & $0.23 \pm 0.03$ \\
\hline \multicolumn{4}{|l|}{ MAD:M } \\
\hline \multicolumn{4}{|l|}{ ETF:QO deficient } \\
\hline 493 & $0.28 \pm 0.09$ & $0.12 \pm 0.03$ & $0.17 \pm 0.08$ \\
\hline 632 & $0.39 \pm 0.10$ & $0.18 \pm 0.02$ & $0.20 \pm 0.06$ \\
\hline 741 & $0.42 \pm 0.08$ & $0.11 \pm 0.03$ & $0.20 \pm 0.03$ \\
\hline \multicolumn{4}{|l|}{ MAD:S } \\
\hline \multicolumn{4}{|l|}{ ETF deficient } \\
\hline 1400 & $0.07 \pm 0.01$ & $0.02 \pm 0.01$ & $0.22 \pm 0.08$ \\
\hline 1401 & $0.13 \pm 0.02$ & $0.05 \pm 0.01$ & $0.25 \pm 0.09$ \\
\hline 1430 & $0.06 \pm 0.03$ & $0.04 \pm 0.02$ & $0.21 \pm 0.07$ \\
\hline 1441 & $0.15 \pm 0.02$ & $0.04 \pm 0.01$ & $0.17 \pm 0.06$ \\
\hline \multicolumn{4}{|l|}{ ETF:QO deficient } \\
\hline 1515 & $0.07 \pm 0.02$ & $0.03 \pm 0.02$ & $0.18 \pm 0.10$ \\
\hline 1520 & $0.15 \pm 0.01$ & $0.03 \pm 0.02$ & $0.18 \pm 0.08$ \\
\hline 1540 & $0.08 \pm 0.02$ & $0.04 \pm 0.01$ & $0.26 \pm 0.05$ \\
\hline
\end{tabular}

* The number of determinations ranged from 25 to 44 for controls and two to 10 for individual MAD cultures.

$75 \%(930)$ of control levels and averaged $54 \%$ of control $(p=$ $0.03)$.

MAD:S cells demonstrated more severe defects in substrate oxidation, oxidizing radiolabeled butyrate, palmitate, and leucine at $3-10,3-16$, and $7-17 \%$ of control levels, respectively $(p=$ $0.001)$. With both labeled butyrate and palmitate, ETF-deficient MAD:S cells 1400, 1401, 1430, and 1441 demonstrated less severe oxidative defects (9-10\% of control) than did ETF:QO deficient cells $1515,1520,1540$ (3-4\% of control; $p=0.02)$. With $\mathrm{L}-\left[2-{ }^{14} \mathrm{C}\right]$ leucine as substrate, oxidation in the former cells was $15 \%$ of control, in the latter $9 \%$ of control, and did not differ significantly between the two groups $(p=0.16)$.

We obtained similar results upon measuring the incorporation of ${ }^{14} \mathrm{C}$ from radiolabeled fatty acids into the cellular protein of intact fibroblasts (Table 4). In the ETF:QO-deficient MAD:M patients 493,632 , and $741,{ }^{14} \mathrm{C}$ incorporation from ${ }^{14} \mathrm{C}$-butyrate and -octanoate averaged 55 and $57 \%$ of control, respectively ( $p$ $=0.05)$. In MAD:S patients, residual activities were somewhat higher than those in the ${ }^{14} \mathrm{CO}_{2}$ production assay, ranging from 9 to $22 \%$ of control with both substrates $(p<0.01)$. This less sensitive assay system did not clearly distinguish the ETF-deficient from the ETF:QO-deficient MAD:S patients.

We also performed fibroblast oxidation studies with the parents of both ETF- and ETF:QO-deficient MAD:S patients, comparing these parental cells to both normal infants and normal adults (Table 5). $\left[1-{ }^{14} \mathrm{C}\right]$ butyrate oxidation in all parental cells was indistinguishable from that in adult controls, but averaged $51 \%$ of the infant controls $(p<0.05)$. Similarly, parental cultures catabolized $\mathrm{L}-\left[2-{ }^{14} \mathrm{C}\right]$ leucine at $60 \%$ of infant control levels $(p<$ 0.05 ), but were indistinguishable from the normal adults. We found somewhat higher residual oxidative activities for both substrates in maternal cultures from three of the four families. This difference is most marked in the mothers of ETF:QOdeficient patients 1515 and 1520 , whose activities were significantly higher than in the corresponding paternal cells $(p<0.05)$. ${ }^{14} \mathrm{C}$-succinate oxidation was identical in all cells. In parental cells, 
Table $5 .{ }^{14} \mathrm{CO}_{2}$ production from labeled substrates by intact parental fibroblasts*

\begin{tabular}{|c|c|c|c|}
\hline Cell cultures & {$\left[1 .{ }^{14} \mathrm{C}\right]$ butyrate } & $\mathrm{L}-\left[2-{ }^{14} \mathrm{C}\right]$ leucine & {$\left[1,4-{ }^{14} \mathrm{C}\right]$ succinate } \\
\hline & \multicolumn{3}{|c|}{$\mathrm{nmol}{ }^{14} \mathrm{CO}_{2}$ produced $/ \mathrm{mg}$ protein $/ \mathrm{h} \pm S E M$} \\
\hline Normal infant controls & $6.59 \pm 0.45$ & $1.93 \pm 0.17$ & $1.79 \pm 0.23$ \\
\hline Normal adult controls & $3.61 \pm 0.56 \dagger \ddagger$ & $0.85 \pm 0.09 \ddagger \S$ & $1.82 \pm 0.16 \S$ \\
\hline \multicolumn{4}{|l|}{ ETF-deficient MAD:S } \\
\hline \multicolumn{4}{|l|}{ Proband: 1401} \\
\hline Mother & $3.69 \pm 0.40$ & $1.10 \pm 0.12$ & $2.27 \pm 0.34$ \\
\hline Father & $3.10 \pm 0.46$ & $1.25 \pm 0.16$ & $1.27 \pm 0.30$ \\
\hline \multicolumn{4}{|l|}{ Proband:1441 } \\
\hline Mother & $2.04 \pm 0.46$ & $1.14 \pm 0.21$ & $1.58 \pm 0.13$ \\
\hline Father & $2.50 \pm 0.39$ & $0.98 \pm 0.19$ & $1.95 \pm 0.07$ \\
\hline \multicolumn{4}{|l|}{ ETF:QO-deficient MAD:S } \\
\hline \multicolumn{4}{|c|}{ Proband: 1515} \\
\hline Mother & $7.45 \pm 1.73$ & $1.58 \pm 0.16$ & 2.68 \\
\hline Father & $2.83 \pm 0.50$ & $0.81 \pm 0.09$ & 2.60 \\
\hline \multicolumn{4}{|l|}{ Proband: 1520} \\
\hline Mother & $2.97 \pm 0.37$ & $1.60 \pm 0.24$ & $1.55 \pm 0.31$ \\
\hline Father & $2.10 \pm 0.26$ & $0.87 \pm 0.13$ & $1.32 \pm 0.26$ \\
\hline
\end{tabular}

* The number of determinations ranged from 15 to 29 for pooled control cells and from one to 11 for individual parental cultures.

$\uparrow$ Cultures $S-1,-2,-4$.

$\ddagger$ Difference from infant controls significant at $p<0.05$.

$\S$ All S cells.

${ }^{14} \mathrm{C}$ incorporation into cell protein from ${ }^{14} \mathrm{C}$-butyrate and -octanoate averaged 60 and $45 \%$ of infant controls $(p<0.05)$, but was indistinguishable from the normal adults (data available on request). As in the ${ }^{14} \mathrm{CO}_{2}$ production studies, higher residual activities were found in maternal than in paternal cells in more than three-quarters of the studies. This distinction again appeared more marked in the parents of ETF:QO-deficient patients 1515 and 1520.

We also performed ${ }^{14} \mathrm{C}$-incorporation studies in amniocytes from a subsequent pregnancy of the mother of ETF-deficient MAD:S patient 1401; activity was greater than $106 \%$ of five amniocyte controls with ${ }^{14} \mathrm{C}$-butyrate, -octanoate and -succinate as substrates (data not shown). Organic acid analyses of the amniotic fluid and mother's urine revealed no abnormal metabolites (courtesy of Kay Tanaka, M.D.). The pregnancy was carried to term and the male infant has no clinical or biochemical abnormalities at age 30 months. Fibroblast cultures were not established on this child.

\section{DISCUSSION}

The findings in the ETF-deficient MAD patients 1401, 840, and 930 clearly demonstrate the wide range of clinical and biochemical heterogeneity in patients with this enzymatic defect. Patient 1401 presented in the neonatal period with acidosis and early death. His clinical course, pathological findings, and urinary metabolites are virtually identical to those of other MAD:S patients and clearly assign him this diagnosis. Patient 840 is neurologically devastated following an episode of acidotic coma and seizures. This patient consistently excreted ethylmalonic acid. His total plasma carnitine levels were in the low normal range and the ratio of esterified to free carnitine was moderately elevated. No precursor loads were performed and riboflavin administration did not produce a lasting decrease in ethylmalonate excretion. Patient 930's findings are more unusual. He excreted only ethylmalonate; adipate excretion was above normal in several samples and increased on MCT loading. Since he had no documented episodes of unexplained coma, lethargy, hypoglycemia, ketosis, or acidosis, his developmental delay may result from some unrecognized prenatal or perinatal insult. While his limited responses to precursor loads seem unexpected in disorders with generalized blocks in acyl-CoA dehydrogenation,
ETF:QO deficient MAD:M patient 741 did not excrete glutarate or medium chain dicarboxylic acids after lysine and MCT challenges (16). The MAD patient described by Verjee and Sherwood (8), who presented at age 6 months, also had a persistent ethylmalonic aciduria, while excretion of adipate and glutarate were intermittent. In summary, the findings in these patients underscore the variability of the MAD:M.

The three patients reported herein $(1401,840,930)$ have not been described previously. In studying their fibroblasts, we thought it informative to investigate MAD cells not yet studied with these techniques $(741,1441,1520$, and 1540) and compare them to MAD cells $493,1400,1430$, and 1515 , studied by others previously $(1,10,12,21)$.

In the MAD:M cells, we find moderate and highly variable defects in oxidation of multiple radiolabeled substrates catabolized via acyl-CoA intermediates. Frerman (personal communication) found intermediate ETF:QO deficiencies in patients 493 and 741 (13 and $51 \%$ of control, respectively). We recently demonstrated ETF deficiency in cells 840 and 930 (29 and 38\% of control, respectively; $p<0.05$; Ref. 22). It is not known whether ETF or ETF:QO is rate limiting for electron flux from the acyl-CoA dehydrogenases to coenzyme Q; their measured specific activities cannot be compared directly, due to profound differences in the fibroblast subfractions and assays employed $(13,22)$. However, the activity of each is clearly lower than the summed activities of the six acyl-CoA dehydrogenases from which they accept electrons. Thus, moderate reductions in the activity of either could lead to significant acyl-CoA accumulation, producing clinical symptoms and a characteristic MAD organic aciduria.

The MAD:S cells demonstrated severe and more consistent defects in substrate oxidation, catabolizing labeled butyrate, palmitate, and leucine at less than $17 \%$ of control levels. These results are similar to those of other investigators, where residual oxidation of these and related substrates ranged from 3 to $22 \%$ of control $(1,10,12,21)$. Interestingly, the oxidative defect in the ETF:QO-deficient cells $(1515,1520,1540$; Ref. 13) is 2- to 3-fold more severe than in the ETF-deficient cells (1400, 1401, 1430, 1441; Ref. 22). Lehnert et al. (7) also found similar differences in residual oxidative activities between MAD:S patients KII (ETF:QO deficiency) and 1400 (ETF deficiency). While the etiology of the morphologic abnormalities in the 
ETF:QO-deficient MAD:S patients is not understood, it could be related to the severity of the metabolic block, rather than to its site. Although all known ETF-deficient MAD:S patients have specific abnormalities of the ETF $\alpha$-subunit (23), the clinical significance and/or inheritance of lesions involving the ETF $\beta$ subunit cannot be predicted.

Our studies with parental fibroblasts from four MAD:S families demonstrate that oxidative activities in parents are generally lower than those in normal infants but indistinguishable from normal adults. We find the relatively higher maternal residual oxidative activities perplexing, although no ready explanation is apparent in the literature. These observations also underscore the necessity of using age-matched controls in these and related studies. Frerman and Goodman (13) have demonstrated intermediate levels of ETF:QO activity in fibroblasts derived from parents of ETF:QO-deficient MAD:S patients, consistent with autosomal recessive inheritance in these families. There have been several females affected with ETF deficiency, including patient 1441, a female sibling of patient 1430 (12) (Steinmann $\mathrm{B}$, personal communication), and one other MAD:S patient (B.C.; Dr. Y. Hsia, HI), to whom we have tentatively assigned the diagnosis of ETF deficiency using the ${ }^{3} \mathrm{H}$-palmitate assay $(0.03 \pm 0.01 \mathrm{nmol} / \mathrm{mg}$ protein $/ \mathrm{h} ; 8 \%$ of control $)$. Thus, both ETF:QO- and ETF-deficient MAD:S are most likely autosomal recessive disorders. To date, direct assay of ETF and ETF:QO has been necessary to confirm the diagnosis in suspected MAD patients. We have recently coupled the ${ }^{3} \mathrm{H}$-palmitate oxidation assay to cell fusion and complementation analysis, providing an efficient means of assessing the degree of metabolic block and identifying the biochemical lesion without direct assay. We describe this assay and complementation system more fully elsewhere (24).

Acknowledgments. The authors thank Dr. K. Tanaka for the organic acid analyses in amniotic fluid and maternal urine; Drs. F. Frerman, N. Gregersen, S. Goodman, Y. Hsia, S. Kahler, H. Przyrembel, J.-M. Saudubray, B. Steinman, K. Tanaka, F. Walther and $U$. Wendel for cell lines and biochemical and clinical information from their patients; Ms. K. Henkle and B. Norbeck for technical assistance; and Ms. B. McKean for preparation of the manuscript.

\section{REFERENCES}

1. Przyrembel H, Wendel U, Becker K, Bremer HJ, Bruinvis L, Ketting D, Wadman SK 1976 Glutaric aciduria type II: report on a previously undescribed metabolic disorder. Clin Chim Acta 66:227-239

2. Goodman SI, McCabe EB, Fennessey PV, Mace JW 1980 Multiple acyl-CoA dehydrogenase deficiency (glutaric aciduria type II) with transient hypersarcosinemia and sarcosinuria; possible inherited deficiency of an electron transfer flavoprotein. Pediatr Res 14:12-17

3. Sweetman L, Nyhan WL, Trauner DA, Merritt TA, Singh M 1980 Glutaric aciduria type II. J Pediatr 96:1020-1023

4. Gregersen N, Kolvraa S, Rasmussen K, Christensen E, Brandt NJ, Ebbesen F,
Hansen FH 1980 Biochemical studies in a patient with defects in the metabolism of acyl-CoA and sarcosine: another possible case of glutaric aciduria type II. J Inherited Metab Dis 3:67-72

5. Coude FX, Ogier H, Charpentier C, Thomassin G, Checoury A, AmedeeManesme O, Saudubray JM, Frezal J 1981 Neonatal glutaric aciduria type II: an X-linked recessive inherited disorder. Hum Genet 59:263-265

6. Goodman SI, Stene DO, McCabe EB, Norenberg MD, Shikes RH, Stumpf DA, Blackburn GK 1982 Glutaric aciduria type II: clinical, biochemical and morphological considerations. J Pediatr 6:946-950

7. Lehnert W, Wendel U, Lindermaier S, Bohm N 1982 Multiple acyl-CoA dehydrogenation deficiency (glutaric aciduria type II), congenital polycystic kidneys, and symmetric warty dysplasia of the cerebral cortex in two brothers. I. Clinical and metabolic and biochemical findings. Eur J Pediatr 130:56-61

8. Verjee $\mathrm{ZH}$, Sherwood WG 1985 Multiple acyl-CoA dehydrogenase deficiency: a neonatal onset case responsive to treatment. J Inherited Metab Dis 8(suppl 2):137-138

9. Dusheiko G, Kew MC, Joffe BI, Lewin JR, Path FF, Mantagos S, Tanaka K 1979 Recurrent hypoglycemia associated with glutaric aciduria type II in an adult. N Engl J Med 301:1405-1409

10. Mantagos S, Genel M, Tanaka K 1979 Ethylmalonic-adipic aciduria: In vivo and in vitro studies indicating deficiency of activities of multiple acyl-CoA dehydrogenases. J Clin Invest 64:1580-1589

11. Gregersen N, Wintzensen H, Kolvraa S, Christensen E, Christensen MF, Brandt $\mathrm{NJ}$, Rasmussen $\mathrm{K} 1982 \mathrm{C}_{6}-\mathrm{C}_{10}$-dicarboxylic aciduria: investigations of a patient with riboflavin responsive multiple acyl-CoA dehydrogenation defects. Pediatr Res 16:861-868

12. Niederwiser A, Steinmann B, Exner U, Neuheiser F, Redweik U, Wang M, Rampini S, Wendel U 1983 Multiple acyl-CoA dehydrogenation deficiency (MADD) in a boy with nonketotic hypoglycemia, hepatomegaly, muscle hypotonia and cardiomyopathy. Detection of $\mathrm{N}$-isovalerylglutamic acid and its monoamide. Helv Paediatr Acta 38:9-26

13. Frerman F, Goodman S 1985 Deficiency of electron transfer flavoprotein or electron transfer flavoprotein: ubiquinone oxidoreductase in glutaric acidemia type II fibroblasts. Proc Natl Acad Sci USA 82:4517-4520

14. Sweetman L 1984 Qualitative and quantitative analysis of organic acids in physiologic fluids for diagnosis of the organic acidurias. In: Nyhan WL (ed) Abnormalities in Amino Acid Metabolism in Clinical Medicine. AppletonCentury-Crofts, Norwalk, CT, pp 419-453

15. Goodman S, Frerman F 1984 Glutaric acidaemia type II (multiple acyl-CoA dehydrogenation deficiency). J Inherited Metab Dis 7(suppl 1):33-37

16. Duran M, Walter F, Bruinvis L, Wadman S 1983 The urinary excretion of ethylmalonic acid. What level requires further attention? Biochem Med 29:171-175

17. Rhead W, Moon A, Roettger V, Henkle K $1985{ }^{14} \mathrm{C}$-labeled substrate catabolism by human diploid fibroblasts derived from infants and adults. Biochem Med 34:182-188

18. Rhead W, Amendt B, Fritchman K, Felts S 1983 Dicarboxylic aciduria: deficient $\left[1-{ }^{14} \mathrm{C}\right]$ octanoate oxidation and medium-chain acyl-CoA dehydrogenase in fibroblasts. Science 221:73-75

19. Amendt B, Rhead W 1985 Catalytic defect of medium-chain acyl-coenzyme A dehydrogenase deficiency. J Clin Invest 76:963-969

20. Bohlen P, Stein S, Dairman W, Udenfriend S 1973 Fluorometric assay of proteins in the nanogram range. Arch Biochem Biophys 155:213-220

21. Saudubray J-M, Coude F-X, Demaugre F, Johnson C, Gibson K, Nyhan W 1986 Oxidation of fatty acids in cultured fibroblasts: a model system for the detection and study of defects in $\beta$-oxidation. Pediatr Res 16:877-881

22. Amendt B, Rhead W 1986 The multiple acyl-CoA dehydrogenation disorders, glutaric aciduria type II and ethylmalonic adipic aciduria: mitochondrial fatty acid oxidation, acyl-CoA dehydrogenase and electron transfer flavoprotein activities in fibroblasts. J Clin Invest 78:205-213

23. Ikeda Y, Keese S, Tanaka K 1985 Molecular heterogeneity of electron transfer flavoprotein (ETF) in glutaric acidemia type II due to an ETF deficiency. Pediatr Res 19:249A

24. Moon A, Rhead W 1987 Complementation analysis of fatty acid oxidation disorders. J Clin Invest 79:59-64 